\title{
Arrhythmia insensitive inversion recovery preparation (IR-prep) with real-time adaptive inversion delay ( $\mathrm{TI})$ :phantom validation Ramkumar Krishnamurthy*1, Amol Pednekar², Jouke Smink³, Benjamin Cheong ${ }^{4}$ and Raja Muthupillai ${ }^{4}$
}

\author{
Address: ${ }^{1}$ Rice University, Houston, TX, USA, ${ }^{2}$ Philips Healthcare, Houston, TX, USA, ${ }^{3}$ Philips Healthcare, Best, Netherlands and ${ }^{4}$ St. Luke's \\ Episcopal Hospital, Houston, TX, USA \\ * Corresponding author
}

\author{
from 13th Annual SCMR Scientific Sessions \\ Phoenix, AZ, USA. 21 -24 January 2010 \\ Published: 21 January 2010 \\ Journal of Cardiovascular Magnetic Resonance 2010, I2(SuppI I):PI 68 doi:10.1 186/I532-429X-I2-SI-PI68
}

This abstract is available from: http://jcmr-online.com/content/I2/SI/PI 68

(C) 2010 Krishnamurthy et al; licensee BioMed Central Ltd.

\section{Introduction}

Typically an ECG-gated 2D IR turbo-field-echo (TFE) sequence is used for myocardial viability imaging. This IRTFE sequence is robust if every RR-interval matches the entered heart-rate, and if steady-state longitudinal magnetization $(\mathrm{Mz})$ reached before the first shot remains the same throughout the acquisition. In real-world, the RRintervals are variable and this variability can introduce substantial amount of artifacts in the resulting image (See Figure 1A, 1B). We hypothesize that it is feasible to reduce the artifacts resulting from variations in the RR interval. The paper describes the method, as well as tests the theoretical predictions in a phantom model.

\section{Purpose}

Unlike saturation recovery (SR) preparation, IR-prep is sensitive to cardiac arrhythmias. The purpose of this paper is to describe an arrhythmia insensitive IR-prep method that is suitable for clinical applications such as myocardial viability imaging.

\section{Materials and methods}

All experiments were performed on a $1.5 \mathrm{~T}$ MR scanner (Philips Healthcare), and a patch was created with the following changes. The TI necessary to null the signal from a specific tissue is given by: $\mathrm{TI}=\ln (2 /(1+\exp (-\mathrm{RR} / \mathrm{T} 1))) * \mathrm{~T} 1$. The TI for each shot of the IR-TFE shot was adaptively adjusted in real-time based on the record of the most recent RR interval.

\section{Phantom study}

An agarose gel phantom mimicking the LV cavity and the surrounding was designed, and imaged using an IR-TFE sequence with the following parameters: TR/TE $/ \alpha=5.1 /$ 2.5/15 ${ }^{\circ} \mathrm{ms}$; Voxel-size: $1.6^{*} 1.6 * 8 \mathrm{~mm}$; TFE factor $=14$; $\mathrm{BW} /$ pixel $=309 \mathrm{~Hz}$. Total scan duration: $18 \mathrm{RR}$ intervals. Arrhythmias mimicking clinical reality were generated using a software driven ECG synthesizer.

\section{Results}

Representative IR-TFE images acquired without any arrhythmias and with arrhythmias without adaptive TI correction, and with adaptive TI correction are shown in Figure (1C, D and $1 \mathrm{E}$ - left to right). Note the substantial reduction in the ghosting artifacts in the image with adaptive TI correction. The myocardial-to-blood CNR was 73\% lower without adaptive TI correction than with TI correction. The ghost artifact intensities dropped by $180 \%$ with adaptive TI correction when compared with intensities measured without adaptive TI.

\section{Conclusion}

The results from the study show that it is feasible to diminish artifacts arising from arrhythmias in an IR-TFE sequence by adaptively adjusting the TI in real-time based on the most recent RR interval. The elimination of these artifacts can improve the myocardial-to-blood CNR as well as decrease artifact intensity. 


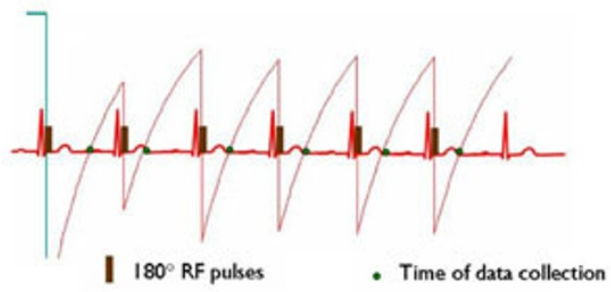

(A) - Normal heart rhythm

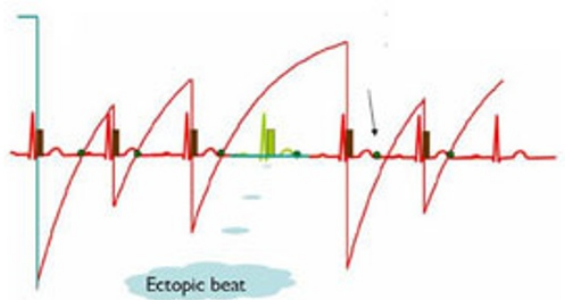

(B) - Change in $\mathrm{Mz}$ with missed RR interval

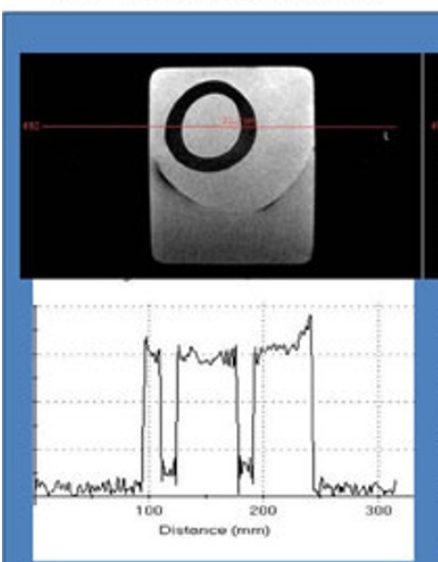

(C)

Normal Heart Rhythm All RR intervals $=1000 \mathrm{~ms}$

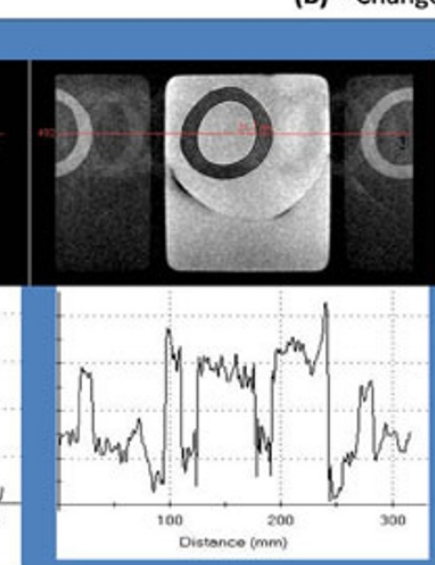

(D)

Figure I

Publish with Bio Med Central and every scientist can read your work free of charge

"BioMed Central will be the most significant development for disseminating the results of biomedical research in our lifetime. " Sir Paul Nurse, Cancer Research UK

Your research papers will be:

- available free of charge to the entire biomedical community

- peer reviewed and published immediately upon acceptance

- cited in PubMed and archived on PubMed Central

- yours - you keep the copyright
BiolMedcentral 